\title{
An Extended TAM for Subscribers' Adoption of Mobile Data Services Provided by Wireless Communication Systems
}

\author{
Jiayin Qi, Huaying Shu, and Jianqiu Zeng \\ Economics and Management School, Beijing University of Posts and \\ Telecommunications, $10 \mathrm{Xi}$ Tu Cheng Road, Haidian District, Beijing, \\ China, 100876 \\ ssfqjy@263.net, \\ shuhy@bupt.edu.cn, \\ Zengianqiu@sohu.com, \\ WWW home page: http://www.sem.bupt.cn
}

\begin{abstract}
Wireless communication systems are one kind of EIS (Enterprise Information Systems) for mobile carriers. One of the major applications of wireless communication systems is to provide mobile data services to subscribers. Why do subscribers use mobile data services? The answer is crucial to the improvement of wireless communication systems. This study applies TAM (Technology Acceptance Model) and mobile subscriber experience factors to predict subscriber's acceptance of mobile data services. The proposed model was empirically evaluated using survey data collected from 802 mobile subscribers. The results reveal that subscribers' perceived ease-of-use and innovation experience are the main reasons to influence their intention of using mobile data services, subscribers' perceived usefulness and brand experience are the key factors to change their attitude toward using mobile data services. Overall, considered direct and indirect effects, subscribers' voice experience and innovation experience are the most important factors influencing their intention of using mobile data services. The implication and the future work of this study are discussed.
\end{abstract}

\section{Acknowledgements}

Research of this paper is funded by the National Natural Science Foundation of China (Project No.70371056) and the Key Laboratory of Information Management \& Information Economy of Ministry of Education of the People's Republic of China.

Please use the following format when citing this chapter: 


\section{Reference}

1. S.Y. Hung, C.M. Chang, User Acceptance of WAP Services: Test Of Competing Theories, Computer Stand \& Interfaces 27(4), 359-370 (Apr 2005).

2. Margherita Pagani, Determinants of Adoption Of Third Generation Mobile Multimedia Services, Journal of Interactive Marketing 18(3), 46-59 (Summer 2004).

3. M. Kleijnen, K. Ruyter and M. Wetzels, Consumer Adoption of Wireless Services: Discovering the Rules, While Playing the Game, Journal of Interactive Marketing 18(2), 51 61 (Spring 2004).

4. G. Hackbarth, V. Grover and M.Y. Yi, Computer Playfulness and Anxiety: Positive and Negative Mediators of the System Experience Effect on Perceived Ease of Use, Information \& Management 40, 221-232 (2003).

5. C.L. Hsu, H.P. Lu. Why Do People Play On-Line Games? An Extended TAM with Social Influences and Flow Experience, Information \& Management 41, 853-868 (2004).

6. S. S. Liaw, Understanding User Perceptions of World-Wide Web Environments, Journal of Computer Assisted Learning 18, 137-148 (2002).

7. F.D. Davis, Perceived Usefulness, Perceived Ease of Use, and User Acceptance of Information Technologies, MIS Quarterly 13(3), 319-340 (1989).

8. F.D. Davis, R. Bagozzi and P.R. Warshaw, User Acceptance of Computer Technology: A Comparison of Two Theoretical Models, Management Science 35(8), 982-1003 (1989).

9. P. Legris, J. Ingham and P. Collerette. Why do People Use Information Technology? A Critical Review of the Technology Acceptance Model, Information \& Management 40, 191204 (2003).

10.F.D. David, User Acceptance of Information Technology: System Characteristics, User Perceptions, and Behavioral Impacts, International Journal of Man Machine Studies 38, 475487 (1993).

11.K. Mathieson, Predicting User Intentions: Comparing the Technology Acceptance Model with the Theory of Planned Behavior, Information Systems Research 2(3), 173-191 (1991).

12.S. Taylor and P. Todd, Understanding Information Technology Usage: A Test of Competing Models, Information Systems Research 6(2), 144-176 (1995).

13.A. Bajaj and S.R. Nidumolu, A Feedback Model To Understand Information System Usage, Information and Management 33, 213-224 (1998). 